\title{
High-Volume Hemofiltration in Sepsis and SIRS: Current Concepts and Future Prospects
}

\author{
Patrick M. Honore ${ }^{\mathrm{a}}$ Olivier Joannes-Boyau ${ }^{c} \quad$ Willem Boer $^{\mathrm{d}} \quad$ Vincent Collin $^{\mathrm{b}}$ \\ a St-Pierre Para-University Hospital, Ottignies-Louvain-la-Neuve, and b European Hospital St-Michel,

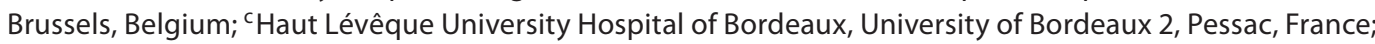 \\ dAtrium Medical Center, Heerlen, The Netherlands
}

\section{Key Words}

Hemofiltration - Sepsis • Acute kidney injury • High-volume hemofiltration - Continuous renal replacement therapy • Dialysis $\cdot$ Systemic inflammation response syndrome

\begin{abstract}
In recent years, a number of techniques have been studied and developed in the field of renal replacement therapy in the septic patient. Manipulation of ultrafiltrate dose, membrane porosity, mode of clearance, and combinations of techniques have yielded promising findings. However, at present, conclusive evidence based on well-designed, randomized controlled trials remains scarce, limiting the practical implementation of many techniques in daily practice outside the context of a study. From the few well-designed and documented studies that we have so far, it is safe to say that optimalization of delivered dose in renal replacement therapy has a proven positive effect. An ultrafiltration rate between 35 and $45 \mathrm{ml} / \mathrm{kg} / \mathrm{h}$, with adjustment for predilution and down time, can be recommended for the septic patient until other data are available. The results of further dose outcome studies with higher ultrafiltration rates will likely be the stepping stone to further improvements in daily clinical practice.

Copyright $\odot 2009$ S. Karger AG, Basel
\end{abstract}

\section{KARGER}

Fax +4161306 1234 E-Mail karger@karger.ch www.karger.com
(C) 2009 S. Karger AG, Basel

0253-5068/09/0281-0001\$26.00/0

Accessible online at:

www.karger.com/bpu

\section{Introduction}

In spite of major recent therapeutic improvements, septic shock does remain a leading cause of mortality in intensive care [1]. It has been advocated for more than a decade $[2,3]$ that the reduction of cytokines in the blood compartment could, in theory, lead to a reduction in mortality in the septic patient. In spite of this immunomodulation sepsis hypothesis, standard hemofiltration was still provided at 1 or 2 liters/h of ultrafiltration and only in the predilution mode for almost 15 years on. Practice began to change as results from new studies that were published in the early 2000s demonstrating a beneficial effect on outcome of increasing the ultrafiltration rate to $35 \mathrm{ml} / \mathrm{kg} / \mathrm{h}$ in patients with acute kidney injury (AKI). Two methods of high-volume hemofiltration (HVHF), with different underlying concepts and results, became prevalent: continuous high-volume hemofiltration (CHVH) providing $50-70 \mathrm{ml} / \mathrm{kg} / \mathrm{h} 24 \mathrm{~h}$ a day, and intermittent high-volume hemofiltration (IHVH) with brief, very-high-volume treatment at $100-120 \mathrm{ml} / \mathrm{kg} / \mathrm{h}$ for $4-$ $8 \mathrm{~h}$ (previously called 'pulse' HVHF). Two recently published studies highlight the crucial role of adequate dosage of continuous venovenous hemofiltration $(\mathrm{CVVH})$, demonstrating that, in critically ill patients with renal failure, a dose of $35 \mathrm{ml} / \mathrm{kg} / \mathrm{h}$ was associated with dramat-

Patrick Honore, MD, ICU Director

St-Pierre Para-University Hospital

Avenue Reine Fabiola, 9, BE-1340 Ottignies-Louvain-la-Neuve (Belgium)

Tel. +32 10437 346, Fax +32 10437123

E-Mail Pa.honore@clinique-saint-pierre.be or Pathonor@skynet.be 
ic improvement in survival of nearly $20 \%$. The incorporation of the results from these studies into daily clinical practice can now be deemed to be urgent, although the results of other ongoing confirmatory (or not) studies are awaited. In a world increasingly guided by evidencebased medicine, two level I studies lead to a grade A recommendation, and this intervention should, therefore, be applied by every intensivist instigating continuous hemofiltration, while awaiting the results of the ongoing studies. Nevertheless, the implementation process is exposed to a number of potential difficulties. These encompass items such as blood flow requirements, vascular access problems, pre- and postdilution policy, type of membranes used, as well as restitution fluid and the possible need for associated dialysis. Implementation of these findings will necessitate a collaborative network between medical staff members and the entire nursing staff.

\section{Definition}

A recent working party [4] has agreed on two different HVHF definition which have become common nowadays: First, continuous high-volume treatment providing $50-70 \mathrm{ml} / \mathrm{kg} / \mathrm{h} 24 \mathrm{~h}$ a day; and intermittent high-volume hemofiltration with brief, very-high-volume treatment at $100-120 \mathrm{ml} / \mathrm{kg} / \mathrm{h}$ for $4-8 \mathrm{~h}$ that used to be called 'Pulse' high-volume hemofiltration. Both come under the heading HVHF, but their concepts and results are somewhat different as we will outline later on.

\section{Rationale: Three Theories}

As said before, it has been advocated for more than a decade $[2,3]$ that the reduction of cytokines in the blood compartment could, in theory, lead to a reduction in mortality in the septic patient. However, in the knowledge that the pharmacodynamics and pharmacokinetics of cytokines can best be described as complex, it seems unavoidable that such gross oversimplifications do not apply. Indeed, in the peak concentration hypothesis [5-8] described by Ronco and Bellomo, efforts are concentrated on removing mediators and cytokines from the blood compartment in the pro-inflammatory phase of sepsis. It is hoped that by reducing the amount of free cytokines, remote organ and associated damage can be limited, thereby attenuating associated mortality. Changes in mediators and cytokines at interstitial and tissue level are not taken into account in this theory, although that they are of clinical importance. In this setting, techniques that facilitate rapid and substantial removal of mediators are privileged. After an extensive literature review, a model was developed that coupled mediator removal from the blood compartment to changes in interstitium and the blood compartment. This second concept, the threshold immunomodulation hypothesis, sometimes referred to as the Honoré concept $[9,10]$, takes a far more dynamic view of the system. Pro-mediators as well as mediators are removed at interstitial and tissue levels, following removal from the blood compartment, until the threshold point is reached, at which time some pathways and cascades are brought to a complete standstill. At this level, the cascade is subsequently lost and no further harm can be done to the tissue of the organism. However, in clinical practice when applying high-volume hemofiltration, determining this point is fraught with difficulty as there might be significant changes at interstitial and tissue level, while no changes in the blood compartment can be determined. A number of studies using hemofiltration, although observational only, have demonstrated improved hemodynamics and survival in some patients without a significant drop of mediators inside the blood compartment itself [11-13]. It may therefore be concluded that the substantial biological effects of HVHF are obtained without any dramatic fall in plasma cytokine level because cytokine or mediator levels fall at tissue level where they do harm. Although the study done by Klouche et al. [13] was not performed using HVHF (but lower volumes), the results of this study support the theory. This model has not yet shown how HVHF promotes mediator and cytokine flow from tissue and interstitium to the blood compartment. The Mediator Delivery hypothesis [14], otherwise known as the Alexander concept, emphasizes the use of high-volume hemofiltration and high replacement volumes (3-5 liters/h) in particular. Several papers have demonstrated a 20 - to 40 -fold increase in lymphatic flow [15-17] with concomitant substantial drag and displacement of mediators and cytokines to the blood compartment, making them available for removal. Thus, the use of high volumes of replacement fluid might be of great importance, not only for extraction but also to propagate lymphatic transport between the interstitium and tissue on the one hand and the blood compartment on the other. All these theories could be compiled to try to understand the whole action of hemofiltration on the restoration of homeostasis which is the ultimate goal to achieve. To gain a wider view of these theories, we will explore the new paradigm of chaos and complex nonlinear systems in sepsis and SIRS. 


\section{Spectrum of Available Blood Purification Techniques}

A number of blood purification techniques are currently available to the clinician treating sepsis in the ICU. Despite this myriad of different techniques, solute transport is effectuated either by diffusion or convection, ador absorption or a combination of these modalities. In classic intermittent hemodialysis (IHD) and derived techniques utilized in the ICU, diffusion (a concentration gradient across a semi-permeable membrane causes solute transport) is the driving force behind solute removal. In hemofiltration and blood filtration-derived techniques, solute removal is perpetuated by convection (a pressure gradient causes fluid movement across a semipermeable membrane with so-called solute drag), favoring removal of middle molecules. Convection is more effective than diffusion in removing middle molecules. Despite this, there is no firm evidence favoring one form of solute clearance over the other in the septic patient, nor is there evidence favoring a continuous technique above intermittent hemodialysis. However, there is evidence to suggest that if a continuous technique is available, clinicians are more inclined to choose it for the unstable patient [18].

It stands to reason that delivered dose, as in conventional intermittent hemodialysis outside the ICU setting, could influence morbidity and therefore mortality. Consequently, positive results have been described in a number of randomized controlled studies both for intermittent hemodialysis [19], for continuous veno-venous hemofiltration [20] and for a combination of both [21]. However, two smaller randomized control trials (RCT), found no association between survival and ultrafiltration dose $[22,23]$. It should be pointed out that in the study of Bouman et al. [22], 28-day survival in all groups was relatively high as compared to other studies, suggesting that the study population differed from that of other studies. However, severity of illness scores did not support this suggestion. In addition, hospital survival in the Bouman study $(63,49$ and 61, respectively) was comparable to 90-day survival in the Saudan study (59 and $34 \%$, respectively, and 64 and $38 \%$, respectively, if untreated and moribund patients were excluded) [19, 22]. Regarding the study of Tolwani [23] as other studies coming from North-America, delay in starting treatment remains a matter of concern and is so long (as compared to Europe) that one can ask oneself if this delay is not too long in order to still be able to reverse the injury. As mentioned above, a number of observational studies
$[9,13,24]$, with higher fluid replacement in continuous veno-venous hemofiltration (CVVH), seems to demonstrate an additional effect, though methodological restrictions surely apply. A position paper published by an ADQI (Acute Dialysis Quality Initiative) group has underlined that HVHF could be used by clinicians in catecholamine-resistant septic shock (CRSS) (Level V Evidence and Grade E Recommendation) [25, 26]. The same position paper supported extended use of fluid replacement at the $35 \mathrm{ml} / \mathrm{kg} / \mathrm{h}$ in CVVH (D) (Level II Evidence and a Grade C Recommendation) [26]. A recent guideline, based on an updated literature review, and recently published elevates this to a grade A recommendation [27, 28]. Nevertheless, it is difficult at this point to differentiate recommended dose for septic versus nonseptic AKI as in nearly all reported randomized studies, the population studied was a mixture of both types of patient, and therefore, we have to await the results of ongoing trials regarding strictly septic ICU-AKI (acute kidney injury) populations. The knowledge that many mediators have molecular weights exceeding the cut-off points of conventional hemofilters has led to the development of techniques whereby filter porosity is increased [29]. Highpermeability hemofiltration (HPHF) [29-37], super-high flux hemofiltration (SHFHF) [38] and hemoadsorption [30] are examples of these. Indeed, in a pilot study, Morgera et al. [37] demonstrated a decreased dose of norepinephrine in the HPHF group, coupled with a lower plasma levels, with a demonstrable clearance increase in mediators (IL-6, IL-1ra). However, this study, though promising, was not designed to study patient survival, nor was ultrafiltrate replacement rate fully optimized. The use of hemofilters with increased filter porosity is burdened by the potential risk of loss of larger beneficial molecules (drugs, hormones, nutrients, anti-inflammatory components). Because of this, a number of hybrid techniques were developed such as coupled plasma filtration and adsorption (CPFA) [39] and cascade hemofiltration (CCHF) [40], whereby the type of substances removed can be targeted more precisely. In theory, removal of relatively large molecules within a narrow band of molecular weight is then possible in these hybrid techniques. It should be pointed out that, strictly speaking, in some techniques, adsorption is not the appropriate term as blood is flooding through a semipermeable membrane. Therefore, the latter is not the net effect of convective plus oncotic forces that result into the passage of mediators through this kind of device. It is then more appropriate to use the term absorption as chemical and physical forces come into play in this setting [25]. 
Table 1. Summary of the most important studies on HVHF in sepsis and SIRS + ARF during the last decade

\begin{tabular}{|c|c|c|c|c|c|c|}
\hline $\begin{array}{l}\text { First author and year } \\
\text { of publication }\end{array}$ & Patients & Clinical setting & Design & $\begin{array}{l}\text { Dose } \\
\mathrm{ml} / \mathrm{kg} / \mathrm{h}\end{array}$ & Improved survival & $\mathrm{p}$ \\
\hline Bouman [22] (2002) & 106 & SIRS, ARF, MOF & RCT & 48 & no & 0.8 \\
\hline Jiang [48] (2005) & 37 & SAP, sepsis & RCT & 54 & yes & $<0.05$ \\
\hline Laurent [49] (2005) & 61 & O-H-C-A, MI, SIRS & RCT & 200 & yes & 0.018 \\
\hline \multicolumn{7}{|l|}{ Oudemans-van Straaten } \\
\hline [50] (1999) & 306 & SIRS, shock, ARF & P, cohort, UNC & 65 & benefit of Ob vs. Ex Morta & $<0.05$ \\
\hline Piccinni [51] (2006) & 80 & septic shock, ARF, ALI & $\mathrm{R}, \mathrm{UNC}$ & 45 & benefit of Ob vs. Ex Morta & $<0.05$ \\
\hline Honoré I [24] (2000) & 20 & refractory septic shock & $\mathrm{P}$, cohort, UNC & 115 & benefit of Ob vs. Ex Morta & $<0.05$ \\
\hline Honoré II [52] (2006) & 38 & refractory septic shock & P, cohort, UNC & 100 & benefit of Ob vs. Ex Morta & $<0.05$ \\
\hline Cornejo [53] (2006) & 20 & refractory septic shock & P, cohort, UNC & 100 & benefit of Ob vs. Ex Morta & 0.03 \\
\hline Joannes-Boyau [54] (2004) & 24 & abdominal refractory septic shock & P, cohort, UNC & 60 & benefit of Ob vs. Ex Morta & $<0.05$ \\
\hline Ronco [5] (2000) & 425 & ICU-ARF & RCT, subgroup & 45 & yes & $<0.05$ \\
\hline
\end{tabular}

$\mathrm{ALI}=$ Acute lung injury; ARF = acute renal failure; benefit of Ob vs. Ex Morta = benefit of observed versus expected mortality in a prospective cohort uncontrolled study; ICU = intensive care medicine; $\mathrm{MI}=$ myocardial infarction; $\mathrm{MOF}=$ multiple organ failure; $\mathrm{O}-\mathrm{H}-\mathrm{C}-\mathrm{A}=$ out-of-hospital cardiac arrest; $\mathrm{P}=$ prospective; RCT = randomised controlled study; SAP = severe acute pancreatitis; SIRS = systemic inflammatory response syndrome; $\mathrm{UNC}=$ uncontrolled.

\section{Which Technique for Which Theory: An Open Discussion}

In the setting of the peak concentration hypothesis, techniques removing cytokines or mediators from the blood compartment more rapidly and substantially are privileged. Intrinsically, both convective and diffusive techniques are able to clear the blood compartment of mediators. However, in both the threshold immunomodulation hypothesis and the mediator delivery hypothesis, effects are brought to bear outside the blood compartment in the interstitium and at tissue level, whilst in the latter high fluid replacement rate is obligatory. Prominence is then given to high-volume (and possibly veryhigh-volume) techniques as well as a number of hybrid techniques using high fluid replacement, though as yet the conclusions are remaining speculative $[41,42]$. Very high volume is defined by pulse-HVHF over $100 \mathrm{ml} / \mathrm{kg} / \mathrm{h}$ on the condition that pulse is followed by continuous renal replacement therapy (CRRT) at $35 \mathrm{ml} / \mathrm{kg} / \mathrm{h}$ according to the latest proposals from a working party report [4]. In clinical practice, dose most definitely plays an important role, despite the fact that no mode of renal replacement therapy has been proved superior. Both in the paper published by the ADQI group $[25,26]$ and in the recent guidelines put together by Oudemans-van Straaten and coworkers $[27,28]$ did promote an effluent rate of at least 35 $\mathrm{ml} / \mathrm{kg} / \mathrm{h}$ that should be recommended nowadays in CRRT. In IHD, a similar dose corresponds to a single pool Kt/V of 1.4 per day, thereby implying the need for daily IHD in case this mode is chosen [43]. It stands to reason that up to now, the dose recommendations apply to every critically ill patient with AKI whether it is secondary to sepsis or not. In classic hyperdynamic septic shock on the ICU, especially accompanied by acute septic renal injury or acute septic renal failure (based on the RIFLE classification), the results of a number of dose outcome studies (the Renal study in Australia and New Zealand and the IVOIRE study in Europe) are awaited with interest $[44,45]$. RIFLE is an acronym of Risk, Injury, Failure, Loss and End Stage in relation to kidney function [46]. One of these dose outcome studies is not restricted to acute septic injury as the RENAL study did not restrict their inclusion criteria to only septic renal injury but also included non septic injury. The IVOIRE study is ongoing and has the potential to give us important insights for the future, hopefully giving us further tools for optimal dosing in subgroups of septic patients with acute renal injury. Only patients with septic shock plus acute renal injury defined by the RIFLE classification will be included. After computer randomization into two groups, one group will receive 35 versus $70 \mathrm{ml} / \mathrm{kg} / \mathrm{h}$ in the other group. In the light of the findings of the Ronco study [5], in which septic patients in the $45-\mathrm{ml} / \mathrm{kg} / \mathrm{h}$ group tended to have better survival, this study was designated to demonstrate increased overall survival in the higher dose group $(70 \mathrm{ml} / \mathrm{kg} / \mathrm{h})$. This study is now fast approaching the first interim analysis by reaching, in 2009, 150 inclu- 
sions [47]. Finally, we summarized the positive and negative studies regarding specifically HVHF in sepsis or SIRS (systemic inflammation response syndrome) plus AKI (table 1) and ranking those studies with their level of evidence. We chose the studies which had the most scientific merit in terms of design and number of patients included $[5,22,48-54]$.

\section{Mechanism of Action: Hemofiltration as a New Shield against the 'Chaos Theory' and ‘Complex Nonlinear Systems' in Sepsis}

Hemofiltration was first used in AKI, which is an independent factor for increased severity of illness and poor outcome in critically ill patients. Early studies had shown that the mortality rate of patients requiring renal replacement therapy (RRT) for AKI in the ICU was nearly twice as high compared to those without AKI $(62.8$ vs. $38.5 \%)[55,56]$. This suggests, therefore, that AKI is independently responsible for increased mortality, even if RRT is used. In fact, while standard RRT significantly reduced mortality in patients with AKI in comparison with mortality rates before RRT was used, mortality rates were still not as low as in patients without AKI. The new concept of 'purification plasma challenge' was then developed to try to decrease mortality. Systemic infla mmatory response syndrome (SIRS), sepsis and septic shock, and acute pancreatitis are known to be the leading causes of AKI in ICU patients, creating an immunologic disturbance with a cytokine storm. Sepsis and inflammatory pathologies disrupt homeostasis with a cellular and humoral response, generating secretion of cytokines such as interleukins and tumor necrosis factor (TNF)- $\alpha$. Over the years, many attempts have been made to block some parts of the inflammatory cascade or to destroy specific components; some positive results were obtained in animal models but were not translated into clinical benefit [57]. It has been suggested that a large and nonspecific reduction in cytokines in the blood compartment could in theory reduce mortality more than simply concentrating on removing or blocking one specific element [58]. However, this approach is complicated by the fact that neither the pharmacodynamics nor the pharmacokinetics of cytokines and other immune components are well known, not even their precise functions. Some of the leading theories in this field are provided by current experts in hemofiltration. These three concepts have been widely explained before. The conclusions, given before, com- ing from these three theories were developed as follows: Firstly, removing the peak cytokine concentration from the blood circulation during the early phase of sepsis could stop the inflammatory cascade and the accumulation of free cytokines, which are the leading cause of organ damage and homeostasis disruption [58]. Secondly, no crucial reduction in cytokine concentration is observed in the bloodstream during hemofiltration, because cytokines from the organs permanently replace those lost in the blood. Lastly, since cytokines and other immune components are transported by the lymphatic stream, this could explain their removal even though large amounts of cytokines were not found in ultrafiltration fluid [13]. Thus, the use of high volumes of exchange fluid might be the principal motor of cytokine removal. To achieve a wider view of these theories, we need to explore the new paradigm of chaos and 'complex non-linear systems' in sepsis and SIRS [59]. The principal goal underlying these theories is not only removal of cytokines but also immunomodulation and control of the inflammatory response, which becomes deleterious when it surpasses its designed purpose. Indeed, the immune response of the host against septic aggression could be compared to a complex nonlinear system which is defined by the infinite number of possible actions in response to a lone stimulus. In a complex nonlinear system, e.g. the situation by which a flight of butterflies in China can change the weather in Boston 3 days later, a bacterial attack or cytokine secretion will have repercussions in the whole body. This explains why homeostasis is not a state of stability per se but rather the ability to stay stable while the status is permanently changing. Yet this incredible adaptability is halted when the system is drowned by an excess of information and when the 'endocrine effect' of cytokines and other immune messages are lost in the storm [60, 61]. The resources of the body system become depleted, and the complex nonlinear system becomes a linear system, with only one course of action. This heralds the onset of multiple organ dysfunction syndrome. It may be that hemofiltration could play a role at this point by decreasing the cytokine storm and by allowing the efficacy of the immune messages to be recovered. Thus, the system's own resources increase, allowing a return of the complex nonlinear system and restored homeostasis. 


\section{Recent Animal Trials and Clinical Studies Highlighting the Crucial Roles of Dosing and Timing}

Studies have shown benefits in terms of survival when 'early' and 'large' hemofiltration doses were applied in septic animals. Early use of hemofiltration has been thoroughly investigated in animal models $[62,63]$. In most of the earlier studies, hemofiltration was used before or just after the injection of a bolus or even before the infusion of endotoxin. It was only in the late 1990s that investigators started to wait about $6-12 \mathrm{~h}$ before using HVHF after a sepsis challenge, thereby 'allowing' the animals to become extremely ill, hemodynamically unstable, and to develop early multiple organ dysfunction before starting hemofiltration [64]. In this way, animal models were able to 'mimic' some aspects of the clinical situation. Only animal models in which HVHF was applied early proved to be very beneficial (some spectacularly), mainly due to the fact that in addition to early application, the investigators administered a much 'stronger' dose of HVHF. However, the differences between human and animal models do not allow these results to be extrapolated to humans. One of the greatest remaining problems with human studies (and especially the mechanistic studies) is the fact that the number of patients is very limited since the technique is so expensive. Moreover, clinical studies have fallen far short of the mean exchange obtained in animal models (only $40 \mathrm{vs.} 100 \mathrm{ml} / \mathrm{kg} / \mathrm{h}$ in animal studies) [33]. As a consequence, many effects seen in animal models can never be reproduced in human settings owing to the use of inadequate doses of HVHF. On the other hand, there is huge variability between clinical trials concerning the range of doses applied, ranging from 1- to 15-fold in the recent studies [33]. The foundations of the high-volume technique were laid by Ronco et al. [5] who showed that in their subgroup of sepsis patients, increasing the volume of treatment from 35 to $45 \mathrm{ml} / \mathrm{kg} / \mathrm{h}$ could improve outcome. That study effectively demonstrated that hemofiltration could be considered as a viable medication in the ICU. The volume of treatment not only has to be adapted to body weight but also to the severity of illness of ICU patients. If nonseptic acute renal failure is being treated, then a lower dose may be optimal; however, a septic patient with AKI may need a higher dose close to 50 or $70 \mathrm{ml} / \mathrm{kg} / \mathrm{h}$ and perhaps even higher or with different modalities for catecholamine-resistant septic shock, refractory hypodynamic septic shock, or even severe acute pancreatitis. At the end of the 1990s, Journois et al. [65] used HVHF $(100 \mathrm{ml} / \mathrm{kg} / \mathrm{h})$ in 20 children during cardiac surgery and reported a reduction in postoperative blood loss, earlier extubation time, and reduced cytokine plasma levels. The first large study using pulse HVHF, at about $100 \mathrm{ml} / \mathrm{kg} / \mathrm{h}$ for 4 consecutive hours (then $35 \mathrm{ml} /$ $\mathrm{kg} / \mathrm{h}$ ), was in 20 septic patients with refractory hypodynamic shock $[24,66]$. In this study, pulse HVHF-treated patients had a dramatically increased survival compared with classical treatment. The observed mortality (55\%) was significantly lower than that predicted by two severity scores (79\%). However, some patients were hemodynamic non-responders (9/20) with disastrous mortality rates. At the same time, a monocenter study by Oudemans-van Straaten et al. [50], with a prospective cohort design of mainly cardiac surgery patients with oliguria (306 patients), showed an observed mortality that was statistically lower in the group treated with intermittent HVHF with a mean volume of 3.8 liters/h (nearly $50 \mathrm{ml} /$ $\mathrm{kg} / \mathrm{h}$ for a $70-\mathrm{kg}$ patient) than the predicted mortality evaluated by three validated severity scores. Studies in the early 21st century concentrated on effects on hemodynamic response and cytokine removal; for example, Cole et al. [67] showed interesting hemodynamic improvement in septic patients treated by HVHF. Recently, a South American team headed by Cornejo [53] did a study similar to that by Honoré et al. [24] and obtained comparable results. They created an algorithm based on the international recommendations for sepsis treatment and incorporated intermittent HVHF $(100 \mathrm{ml} / \mathrm{kg} / \mathrm{h}$ for a single 12-hour period) as a salvage therapy for patients in refractory septic shock [53]. However, as in the study by Honoré et al. [24], although the observed mortality (40\%) was lower than the expected one $(60 \%)$, there was also a responder and a nonresponder group. In contrast, Joannes-Boyau et al. [54] studied the effect of HVHF at $50 \mathrm{ml} / \mathrm{kg} / \mathrm{h}$ maintained for $96 \mathrm{~h}$ in patients with septic shock with multiple organ dysfunction syndrome, and found that, although results in terms of mortality were comparable to those in previous studies (45\% observed vs. $70 \%$ predicted), all the patients were hemodynamic responders. A retrospective study by Piccinni et al. [51] recently reported the same results with HVHF maintained at $45 \mathrm{ml} / \mathrm{kg} / \mathrm{h}$ in 40 septic patients, in comparison with a historical group who were treated by standard CVVH. Finally, a prospective study by Ratanarat et al. [68] confirmed the earlier results of Honoré et al. [24] and Cornejo et al. [53], with a similar protocol of pulse HVHF $(85 \mathrm{ml} / \mathrm{kg} / \mathrm{h}$ for $6-8 \mathrm{~h})$ in 15 septic patients with multiple organ dysfunction syndrome. All these studies were only single center, nonrandomized and uncontrolled, but they all showed the same results and proved that HVHF can be delivered safely. The sole difference in results among 
the studies is in the occurrence of hemodynamic responders and nonresponders in studies using intermittent hemofiltration which was not reported in studies using the continuous method. In a single study comparing HVHF with standard CVVH conducted by Bouman et al. [22], 106 patients were randomized into three groups - early HVHF (within the first $12 \mathrm{~h}$ of AKI), early standard CVVH, and late standard CVVH. There were no differences in terms of 28-day mortality or recovery of renal function, but no statistical conclusions could be drawn owing to the lack of power, with only 35 patients in each group. Indeed, the very specific patient population, most coming from cardiac surgery, perhaps explains the low mortality rate, making the possibility of finding any statistical differences among the groups even more remote. Several studies, in particular in Asia, have also explored the effects of HVHF in severe acute pancreatitis. Wang and coworkers in animals [69] and humans [70] and Jiang et al. [48] in humans demonstrated the clinical benefit of HVHF in this context. They studied the effects of HVHF alone, or in comparison with standard CVVH, on mortality and organ function recovery and showed a clear benefit in using high volumes with early initiation. While all these studies were promising, it is now time for larger studies and randomized controlled trials. The results from one such study, the so-called VA/NIH study, were published in 2008 [71]. This was a very large and well-conducted randomized study comparing two different doses of CRRT ( $20 \mathrm{vs.} 35 \mathrm{ml} / \mathrm{kg} / \mathrm{h}$ ) and two different intensities of intermittent RRT depending on the hemodynamic status of the patient; nevertheless, several criticisms have been made $[72,73]$, including the supposed $35-\mathrm{ml} / \mathrm{kg}$ dose of CVVH in the intensive-treated group which was split into $18 \mathrm{ml} / \mathrm{kg} / \mathrm{h}$ of dialysis $(1,500 \mathrm{ml} / \mathrm{h})$ and $17 \mathrm{ml} / \mathrm{kg} / \mathrm{h}$ of convection rate, giving an actual dose of roughly $13 \mathrm{ml} / \mathrm{kg} / \mathrm{h}$ (when taking to account the predilution modality instead of full postdilution). Additionally, the patients were enrolled in the study after being a mean of roughly 7 days in the ICU and roughly 10 days in the hospital which represents a considerably longer delay in treatment than used in any other study. Of note also, more than $65 \%$ of the patients received either intermittent hemodialysis or sustained low-efficiency dialysis (SLED) treatment within $24 \mathrm{~h}$ prior to the randomization. Needless to say, the results of the ANZICS clinical trials group renal study (clinicaltrials.gov number NCT00221013) [44] comparing augmented with normal RRT in severe acute renal failure are eagerly awaited. A recent animal study has also highlighted the direct action of hemofiltration on the cellular mitochondria of the sep- tic myocardium [74]. Indeed, this study was able to demonstrate that hemofiltration could reverse the negative effects of sepsis on myocardial mitochondrial respiratory chain complex activity in porcine septic shock [74]. This study could be seen as the missing link between the hemodynamic effects of HVHF and what is happening beyond in order to improve mortality.

Recent investigations have suggested that there are perhaps synergistic effects between HVHF and enhanced adsorption in order to restore sepsis-induced immunodysregulation $[75,76]$.

\section{Practical Aspects for the Bedside Clinician}

New treatment volumes imply changes in hemofiltration practice so as to guarantee the efficacy and safety of the technique. Indeed, to reach 60 or $100 \mathrm{ml} / \mathrm{kg} / \mathrm{h}$ of treatment volume, important principles need to be respected. First, a high blood flow is necessary to maintain a filtration fraction below $25 \%$, a level above which 'protein cake' clogging in the membrane becomes a major concern. In our practice, in order to attain an exchange flow of $35 \mathrm{ml} / \mathrm{kg} / \mathrm{h}$ even in very heavy patients (up to 120 $\mathrm{kg}$ ), we have, for nearly 8 years, used a constant high blood flow of $300 \mathrm{ml} / \mathrm{min}$ which allows the clinician to run a hemofiltration device at $35 \mathrm{ml} / \mathrm{kg} / \mathrm{h}$ with a filtration fraction below $25 \%$ even in patients with a body weight of $120 \mathrm{~kg}$ as long as the blood flow is equal to 300 $\mathrm{ml} / \mathrm{min}$. However, to attain such a blood flow, excellent vascular access is required, with a large catheter (13.5 or $14 \mathrm{Fr}$ ), using an adequate location (right jugular is the best followed by femoral approach, while the subclavian route should not to be used) [77] and good structure (coaxial with $360^{\circ}$ arterial intake). Second, the best restitution fluid is probably buffered bicarbonate and should be administered $1 / 3$ in predilution and $2 / 3$ in postdilution, i.e. the best compromise between loss of treatment efficacy and optimization of blood rheology [78]; in patients with citrate anticoagulation, the proportions of pre- and postdilution might be different [79]. The choice of membrane is also primordial and a highly biocompatible synthetic filter with a high exchange surface is recommended (1.7$2.1 \mathrm{~m}^{2}$ ). Temperature control is not important with low fluid exchange volumes but becomes essential when the volume increases dramatically. Two systems are possible for temperature control: heating the fluid before restitution or heating the blood directly. Empirically, heating the replacement fluid seems preferable to heating the blood, owing to possible deleterious effects of high tem- 
peratures on the blood. However, to date no problems have been recorded and the two systems have demonstrated their safety and efficacy. The new machines specifically dedicated to high volumes have extremely sensitive and precise pressure control and volume balance functions. Furthermore, it is important to stay in the normal pressure range for optimal use of high-flow hemofiltration. Indeed, staying below $-120 \mathrm{~mm} \mathrm{Hg}$ of arterial pressure is indicative of a catheter problem and likely early machine failure. The same is true with a venous line, where high pressure indicates catheter or bubble trap clotting. The transmembrane pressure reflects the state of clogging in the filter, while a high pressure indicates that many fibers are clogged. To alleviate the pressure problem, it is recommended that treatment is stopped when the patient is being nursed or moved, especially with high volumes. HVHF also requires adequate management and control of fluid exchange and small solutes. In fact, small molecules are largely removed during hemofiltration and strict monitoring of sodium, potassium, phosphorus, glucose and acid-base balance is mandatory. Detection of infection during hemofiltration may be difficult as this technique can blunt hyperthermia, but recent studies have shown interesting new tools for early detection of infection in these conditions [80]. Adaptation of antimicrobials during HVHF is also crucial in order to avoid underdosing [81]. Finally, on-line techniques may be crucial in the future [82]. Widespread application of fluid substitution in hemofiltration at $35 \mathrm{ml} / \mathrm{kg} / \mathrm{h}$ remains surprisingly lacking; despite the evidence, recent unpublished surveys have shown that less than $50 \%$ of units are applying this scientifically sound regimen.

\section{Future Directions regarding the Use of Hemofiltration in Sepsis}

In terms of recommendations for clinical practice, patients with non-septic AKI should receive a renal replacement dose of at least $35 \mathrm{ml} / \mathrm{kg} / \mathrm{h}$ (level II evidence and grade $\mathrm{C}$ recommendation) [25] and probably a higher dose if they have septic AKI or even more with septic shock plus AKI. As discussed earlier, the VA/NIH study did not have enough power to change this recommendation in view of its shortcomings $[72,73]$. Catecholamineresistant septic shock, either hypo- or hyperdynamic, could be seen as an indication for HVHF (level V evidence and grade E recommendation) for clinicians experienced in HVHF therapies [25, 27, 28]. However, HVHF should be integrated into practice algorithms for use as a salvage therapy in ICUs as no other treatment has proved its efficacy in these patients with a very high risk of mortality [53]. HVHF should be reserved for patients with AKI; although the benefit of early treatment has been shown, initiating RRT before renal injury is not yet recommended. In fact, the best time to start hemofiltration may be the renal injury state (creatinine $\times 2$ from baseline or oliguria $<0.5 \mathrm{ml} / \mathrm{kg}$ over the preceding $12 \mathrm{~h}$ ) from the RIFLE classification which could represent the best compromise between early initiation and renal impairment [83]. To evaluate HVHF, more, larger prospective randomized studies are needed which must respect certain conditions. First, the safest technique must be used, but this requirement is the easiest to meet as new hemofiltration machines are much safer and more efficient. Second, we need to define the exact time to start hemofiltration in relation to the start of sepsis and AKI. The best policy is to use a common classification for AKI, such as RIFLE, and to start in the first $24 \mathrm{~h}$ following the onset of sepsis. Third, it is of primordial importance to define the volume of treatment according to body size in $\mathrm{ml} / \mathrm{kg} / \mathrm{h}$. Finally, we should develop a greater understanding of the mechanisms of sepsis and SIRS in order to identify the targets for HVHF. In future trials, it would be interesting to detect any potential interference or possible synergy between $\mathrm{HVHF}$ and activated protein C, for example. The best design for the use of hemofiltration still remains to be defined and the sequences and the duration of high-volume 'rushes' need to be established [84]. Although prolonged HVHF seems more able to stop the initial inflammatory storm and late immunoparalysis, the efficiency and practicability of pulse high volume should be explored. While several large randomized trials are currently in progress investigating hemofiltration doses in AKI patients, only one is comparing HVHF with standard CVVH (The IVOIRE (hIgh VOlume in Intensive caRE) study, clinicaltrials.gov ID NCT00241228) [85]. This study will try to expand the findings of the initial study by Ronco and colleagues [5] to septic patients. Indeed, this large randomized study will include patients with septic shock plus at least injury stage AKI, as defined by the RIFLE classification. After computerized randomization, patients will receive HVHF at either 35 or $70 \mathrm{ml} /$ $\mathrm{kg} / \mathrm{h}$. This study will try to demonstrate that 'higher' doses (i.e. $70 \mathrm{ml} / \mathrm{kg} / \mathrm{h}$ ) will further improve the survival rate from septic AKI in ICU patients at 28, 60 and 90 days. The first interim analysis will be performed when 150 patients have been included and this is expected to happen sometime in 2009. 


\section{Conclusions}

The use of hemofiltration has steadily increased in the last decade, from a simple treatment for AKI to adjunctive therapy for sepsis or other acute episodes of SIRS, such as acute pancreatitis. The story is continuing to evolve and we can be sure that with the development of further technology and better understanding of the pathology, hemofiltration doses and the efficacy of the machines will be better defined. For the moment, 35 $\mathrm{ml} / \mathrm{kg} / \mathrm{h}$ should be the standard hemofiltration dose in ICUs for all patients with AKI, while in some situations, like sepsis, the dose should be increased as a salvage therapy in view of the high mortality rates in these patients. However, more trials are needed before HVHF can be recommended as routine treatment in ICUs, in order to determine the best scheme of use and to obtain some form of consensus. In recent years, a number of techniques have been studied and developed in the field of
RRT in the septic patient. Manipulation of ultrafiltrate dose, membrane porosity, mode of clearance, and combinations of techniques have yielded promising findings. However, at present, conclusive evidence based on welldesigned, randomized controlled trials remains scarce, limiting the practical implementation of many techniques in daily practice outside the context of a study. From the few well-designed and documented studies that we have so far, it is safe to say that optimalization of delivered dose in RRT has a proven positive effect. An ultrafiltration rate between 35 and $45 \mathrm{ml} / \mathrm{kg} / \mathrm{h}$, with adjustment for predilution and downtime, can be recommended for the septic patient until other data are available. The results of further dose outcome studies with higher ultrafiltration rates will likely be the stepping stone to further improvements in daily clinical practice. Hybrid techniques will also likely have a role in the expanding field of RRT in the septic patient in the near future $[42,86]$.

\section{References}

1 Vincent JL, Atalan HK: Epidemiology of severe sepsis in the intensive care unit. $\mathrm{Br} \mathrm{J}$ Hosp Med 2008;69:442-443.

2 Damas P, Canivet JL, de Groote D, et al: Sepsis and serum cytokines concentrations. Crit Care Med 1997;25:405-412.

3 Casey LC, Balk RA, Bone RC: Plasma cytokine and endotoxin levels correlate with survival in patients with the sepsis syndrome. Ann Intern Med 1993;119:771-778.

4 Honoré PM, Joannes-Boyau O, Kotulak T, et al: Report of the working party on high volume hemofiltration including definitions and classification. Proc 2nd Czech Conference on Critical Care Nephrology, Pardubice, Czech Republic, 2007.

5 Ronco C, Bellomo R, Homel P, Brendolan A, Dan M, Piccinni P, et al: Effects of different doses in continuous veno-venous haemofiltration on outcomes of acute renal failure: a prospective randomised trial. Lancet 2000; 356:26-30

-6 Ronco C, Tetta C, Mariano F, Wratten ML, Bonello M, Bellomo R: Interpreting the mechanism of continuous renal replacement therapy in sepsis: the peak concentration hypothesis. Artif Organs 2003;27:792-801.

7 Brendolan A, D’Intini V, Ricci Z, et al: Pulse high volume hemofiltration. Int J Artif Organs 2004;27:398-403.

-8 Ronco C, Ricci Z, Bellomo R: Importance of increased ultrafiltration volume and impact on mortality: sepsis and cytokine story and the role for CVVH. EDTRA ERCA J 2002;2: 13-18.
-9 Honoré PM, Joannes-Boyau O: High volume hemofiltration (HVHF) in sepsis: a comprehensive review of rationale, clinical applicability, potential indications and recommendations for future research. Int J Artif Organs 2004;27:1077-1082.

10 Honoré PM, Matson JR: Extracorporeal removal for sepsis: acting at the tissue level. The beginning of a new era for this treatment modality in septic shock. Crit Care Med 2004;32:896-897.

11 Honoré PM, Boer W, Joannes-Boyau O, Gressens B: High volume haemofiltration and hybrid techniques in sepsis: new insights into the rationale. Neth J Crit Care 2007;11: 239-242.

12 Honoré PM, Joannes-Boyau O, Gressens B: Blood and plasma treatments: the rationale of high-volume hemofiltration. Contrib Nephrol. Basel, Karger, 2007, vol 156, pp 387-395.

13 Klouche K, Cavadore P, Portales P, Clot J, Canaud B, Beraud JJ: Continuous veno-venous hemofiltration improves hemodynamic in septic shock with acute renal failure without modifying TNF- $\alpha$ and IL- 6 plasma concentrations. J Nephrol 2002;15:150-157.

14 Di Carlo JV, Alexander SR: Hemofiltration for cytokine-driven illness: the mediator delivery hypothesis. Int J Artif Organs 2005;28: 777-786.

15 Olszewski WL: The lymphatic system in body homeostasis: physiological conditions. Lymph Fat Res Biol 2003;1:11-21.
16 Onarherim H, Missavage E, Gunther RA, Kramer GC, Reed RK, Laurent TC: Marked increase of plasma hyaluronan after major thermal injury and infusion therapy. J Surg Res 1991;50:259-265.

17 Wasserman K, Mayerson HS: Dynamics of lymph and plasma protein and exchange Cardiologia 1952;21:296-307.

18 Cho KC, Himmelfarb J, Paganini E, et al: Survival by dialysis modality in critically ill patients with acute kidney injury. J Am Soc Nephrol 2006;17:3132-3138.

-19 Schiffl H, Lang SM, Fisher R: Daily hemodialysis and the outcome of acute renal failure. N Engl J Med 2002;346:305-310.

20 Ronco C,Bellomo R, Homel P, et al: Effects of different doses in continuous veno-venous haemofiltration on outcomes of acute renal failure: a prospective randomised trial. EDTNA ERCA J 2002;(suppl 2):7-12.

-21 Saudan P, Niederberger M, De Seigneux S, et al: Adding a dialysis dose to continuous hemofiltration increases survival in patients with acute renal failure. Kidney Int 2006; 70 : 1312-1317.

22 Bouman CS, Oudemans-Van-Straaten HM, Tijssen JG, Zandstra DF, Kosecioglu J: Effects of early high-volume continuous venovenous hemofiltration on survival and recovery of renal function in intensive care patients with acute renal failure: a prospective, randomized trial. Crit Care Med 2002; 30:2205-2211. 
23 Tolwani AJ, Campbell RC, Stofan BS, et al: Standard versus high-dose CVVHDF for ICU-related acute renal failure. J Am Soc Nephrol 2008;19:1233-1238.

24 Honoré PM, Jamez J, Wauthier M, et al: Prospective evaluation of short term high volume isovolemic haemofiltration on the haemodynamic course and outcome in patients with intractable circulatory failure resulting from septic shock. Crit Care Med 2000;28: 3581-3587.

25 Bellomo R, Honoré PM, Matson JR, Ronco C, Winchester J: Extracorporeal blood treatment (EBT) methods in SIRS/sepsis. ADQI III Conference. Int J Artif Organs 2005;28: 450-458.

26 Bellomo R, Honoré PM, Matson JR, Ronco C, Winchester J: Extracorporeal blood treatment (EBT) methods in SIRS/sepsis. Consensus statement. ADQI III Conference. Electronic Supplement Material, 2005. www. adqi.net.

27 Bouman CS, Oudemans HM: Guidelines for timing, dose, and mode of continuous replacement therapy for acute renal failure in the critically ill. Neth J Crit Care 2006;10: 561-568.

28 Bouman CS, Oudemans-van Straaten HM, Schultz MJ, Vroom MB: Hemofiltration in sepsis and systemic inflammatory response syndrome: the role of dosing and timing. J Crit Care 2007;22:1-12.

-29 Lee PA, Weger G, Pryor RW, Matson JR: Effects of filter pore size on efficacy of continuous arterio-venous haemofiltration therapy for staphylococcus aureus-induced septicaemia in immature swine. Crit Care Med 1998; 26:730-737.

-30 Lee WC, Uchino S, Fealy N, et al: Super high flux hemodialysis at high dialysate flows: an ex vivo assessment. Int J Artif Organs 2004; 27:24-28.

- 31 Honoré PM, Matson JR: Hemofiltration, adsorption, sieving and the challenge of sepsis therapy design. Crit Care 2002;6:394-396.

- 32 Rogiers P. Improved short-term outcomes with early use of isovolemic hemofiltration in patients with septic shock. Nat Clin Pract Nephrol 2006;2:478-479.

33 Honoré PM, Zydney AL, Matson JR: High volume and high permeability haemofiltration in sepsis: the evidences and the key issues. Care Crit Ill 2003;3:69-76.

34 Matson JR, Zydney RL, Honoré PM: Blood filtration: new opportunities and the implications on system biology. Crit Care Resusc 2004;6:209-218.

- 35 Klingel R, Ahrenholz P, Schwarting A, Rockel A: Enhanced functional performance characteristics of a new polysulfone membrane for high-flux hemodialysis. Blood Purif 2002;20:325-333.

-36 House AA, Ronco C: Extracorporeal blood purification in sepsis and sepsis-related acute kidney injury. Blood Purif 2008;26:3035.
37 Morgera S, Haase M, Kuss T, et al: Pilot study on the effects of high cutoff hemofiltration on the need for norepinephrine in septic patients with acute renal failure. Crit Care Med 2006;34:2099-2104.

38 Uchino S, Bellomo R, Goldsmith D, et al: Super high flux hemofiltration: a new technique for cytokine removal. Intensive Care Med 2002;28:651-655.

39 Bellomo R, Tetta C, Ronco C: Coupled plasma filtration adsorption. Intensive Care Med 2003;29:1222-1228.

40 Valbonesi M, Carlier P, Icone A, Accorsi P, Borberg H, Schreiner T, et al: Cascade filtration: a new filter for secondary filtration: a multicentric study. Int J Artif Organs 2004; 27:513-515.

41 Joannes-Boyau O, Honoré PM, Boer W: Hemofiltration: the case for removal of sepsis mediators from where they do harm. Crit Care Med 2006;34:2244-2246.

42 Honoré PM, Joannes-Boyau O, Meurson L, Boer W, Piette V, Galloy AC, et al: The big bang of haemofiltration: the beginning of a new era in the third millennium for extracorporeal blood purification. Int J Artif Organs 2006;29:649-659.

43 Honoré PM, Joannes-Boyau O: 'The French Hemodiafe Trial': not either a decisive nor a definitive study regarding controversy for renal replacement therapy in the ICU field. Int J Artif Organs 2006;29:1190-1192.

44 ANZICS Clinical Trials Group: Last accessed in September 2008. Augmented vs. normal renal replacement therapy in severe acute renal failure (renal study). ClinicalTrials.gov/ct2/show/NCT00221013.

45 Honoré PM, Joannes-Boyau O: The IVOIRE Study: impact of high volume haemofiltration in early septic shock with acute renal injury: a prospective multicentric randomized study. Design presented for the Stoutenbeek Award of the 18th Annual Congress of ESICM Society, Berlin, 2004

46 Bellomo R, Ronco C, Kellum J, Mehta R, Palevsky P, ADQI Work Group: Acute renal failure: definition, outcome measures, animal models, fluid therapy and information technology needs. Second International Consensus Conference of the Acute Dialysis Quality Initiative (ADQI) Group. Critical Care 2004;8:204-212.

47 Joannes-Boyau O, Honoré PM, Boer W, et al: The IVOIRE Study: description of the methodology and the design used. Electronic Supplemental Material. NCT00241228.

-48 Jiang HL, Xhue WJ, Li DK, et al: Influence of continuous veno-venous hemofiltration on the course of acute pancreatitis. World J Gastroenterol 2005;11:4815-4821.

49 Laurent I, Adrie C, Vinsonneau C, et al: High-volume hemofiltration after out-ofhospital cardiac arrest: a randomized study. J Am Coll Cardiol 2005;46:432-437.
-50 Oudemans-van Straaten HM, Bosman RJ, van der Spoel JI, Zandstra DF: Outcome of critically ill patients treated with intermittent high-volume haemofiltration: a prospective cohort analysis. Intensive Care Med 1999;25:814-821.

51 Piccinni P, Dan M, Barbacini S, et al: Early isovolaemic haemofiltration in oliguric patients with septic shock. Intensive Care Med 2006;32:80-86.

52 Honoré PM, Joannes-Boyau O, Merson L, Fleureau C, Roze H, Janvier G: Pulse high volume hemofiltration in septic shock plus acute renal failure (PULSHAR study). Blood Purif 2006;24:267-268 (Abstract).

53 Cornejo R, Downey P, Castro R, et al: Highvolume hemofiltration as salvage therapy in severe hyperdynamic septic shock. Intensive Care Med 2006;32:713-722.

54 Joannes-Boyau O, Rapaport S, Bazin R, Fleureau C, Janvier G: Impact of high volume hemofiltration on hemodynamic disturbance and outcome during septic shock. ASAIO J 2004;50:102-109.

55 Metnitz PG, Krenn CG, Steltzer H, et al: Effects of acute renal failure requiring renal replacement therapy on outcome in critically ill patients. Crit Care Med 2002;30:20512058.

56 Mehta RL, McDonald B, Gabbai FB, et al: Collaborative Group for treatment of ARF in the ICU. A randomized clinical trial of continuous versus intermittent dialysis for acute renal failure. Kidney Int 2001;60:1154-1163.

57 Hotchkiss RS, Karl IE: The pathophysiology and treatment of sepsis. N Engl J Med 2003; 348:138-150.

58 Ronco C, Bellomo R: Acute renal failure and multiple organ dysfunction in the ICU: from renal replacement therapy (RRT) to multiple organ support therapy (MOST). Int J Artif Organs 2002;25:733-747.

59 Seely AJ, Christou NV: Multiple organ dysfunction syndrome: exploring the paradigm of complex nonlinear systems. Crit Care Med 2000;28:2193-2200.

60 Mayer J, Rau B, Gansauge F, Beger HG: Inflammatory mediators in human acute pancreatitis: clinical and pathopysiological implications. Gut 2000;47:542-552.

61 Ertel W, Kremer JP, Kenney J, et al: Down regulation of proinflammatory cytokine release in whole blood from septic patients. Blood 1995;85:1341-1347.

-62 Grootendorst AF, van Bommel EF, van der Hoeven B, van Leengoed LA, van Osta AL: High volume hemofiltration improves right ventricular function in endotoxin-induced shock in the pig. Intensive Care Med 1992;18: 235-240.

63 Grootendorst AF, van Bommel EF, van Leengoed LA, Nabuurs M, Bouman CS, Groeneveld AB: High volume hemofiltration improves hemodynamics and survival of pigs exposed to gut ischemia and reperfusion. Shock 1994;2:72-78. 
64 Rogiers P, Zhang H, Smail N, Pauwels D, Vincent JL: Continuous veno-venous hemofiltration improves cardiac performance by mechanisms other than tumor necrosis factor-alpha attenuation during endotoxic shock. Crit Care Med 1999;27:1848-1855.

65 Journois D, Israel-Biet D, Pouard P, et al: High volume, zero-balanced hemofiltration to reduce delayed inflammatory response to cardiopulmonary bypass in children. Anesthesiology 1996;85:965-976.

66 Honoré PM, Jamez J, Wauthier M, et al: Removal of mediators by hemofiltration in septic shock: where do we stand? Réanim Urgences 2000;9:289-297.

67 Cole L, Bellomo R, Journois D, Davenport P, Baldwin I, Tipping P: High-volume haemofiltration in human septic shock. Intensive Care Med 2001;27:978-986.

-68 Ratanarat R, Brendolan A, Piccinni P, et al: Pulse-high volume haemofiltration for treatment of severe sepsis: effects on hemodynamics and survival. Crit Care 2005;9:294302.

69 Wang H, Zhang ZH, Yan XW, et al: Amelioration of haemodynamics an oxygen metabolism by continuous veno-venous hemofiltration in experimental pancreatitis. World J Gastroenterol 2005;11:127-131.

70 Wang H, Li WQ, Zhou W, Li N, Li JS: Clinical effects of continuous high volume hemofiltration on severe acute pancreatitis complicated with multiple organ dysfunction syndrome. World J Gastroenterol 2003;9: 2096-2099.
1 Palevsky PM, Zhang JH, O’Connor TZ, et al: Intensity of renal support in critically ill patients with acute kidney injury. N Engl J Med 2008;359:7-20.

72 Ronco C, Honoré PM: Renal support in critically ill patients with acute kidney injury. $\mathrm{N}$ Engl J Med 2008;359:1959-1962.

73 Ronco C, Cruz D, Oudemans-van-Straaten HM, Honoré PM, House A, Bin D, Gibney N: Dialysis dose in acute kidney injury: no time for therapeutic nihilism - a critical appraisal of the Acute Renal Failure Trial Network study. E-pub ahead of print.

74 Li CM, Chen JH, Zhang P, et al: Continuous veno-venous haemofiltration attenuates myocardial mitochondrial respiratory chain complexes activity in porcine septic shock. Anaesth Intensive Care 2007;35:911-919.

75 Rimmelé T, Assadi A, Cattenoz M, et al: High-volume haemofiltration with a new haemofiltration membrane having enhanced adsorption properties in septic pigs. E-pub ahead of print.

76 Joannes-Boyau O, Honoré PM, Boer W, Collin V: Are the synergistic effects of high volume haemofiltration and enhanced adsorption the missing key in sepsis modulation? E-pub ahead of print.

77 Mandolfo S, Galli F, Costa S, Ravani P, Gaggia $\mathrm{P}$, Imbasciati E: Factors influencing permanent catheter performance. J Vasc Access 2001;2:106-109.

78 Ricci Z, Ronco C: Pre- versus post-dilution CVVH. Blood Purif 2005;23:338-342.

79 Nurmohamed SA, Vervloet MG, Girbes AR, Ter Wee PM, Groeneveld AB: Continuous venovenous hemofiltration with or without predilution regional citrate anticoagulation: a prospective study. Blood Purif 2007;25: 316-323.
80 Ratanarat R, Cazzavillan S, Ricci Z, et al: Usefulness of a molecular strategy for the detection of bacterial DNA in patients with severe sepsis undergoing continuous renal replacement therapy. Blood Purif 2007;25: 106-111.

-81 Arzuaga A, Isla A, Gascon AR, Maynar J, Corral E, Pedraz JL: Elimination of piperacillin and tazobactam by renal replacement therapies with AN69 and polysulfone hemofilters: evaluation of the sieving coefficient. Blood Purif 2006;24:347-354.

$>82$ Kooman JP, van der Sande FM, Beerenhout CM, Leunissen KM: On-line filtration therapies: emerging horizons. Blood Purif 2006; 24:159-162.

83 Bellomo R, Kellum JA, Mehta R, Ronco C: The Acute Dialysis Quality Initiative II: the Vicenza conference. Adv Ren Replace Ther 2002;9:290-293.

84 Tetta C, Bellomo R, Kellum J, et al: High volume hemofiltration in critically ill patients: why, when and how? Contrib Nephrol. Basel, Karger, 2004, vol 144, pp 362-375.

85 Joannes-Boyau O, Honoré PM: Haemofiltration Study: clinicaltrials.gov ID NCT00241228 (last accessed in September 2008).

86 Honoré PM, Joannes-Boyau O, Gressens B: Blood and plasma treatments: High-volume hemofiltration: a global view. Contrib Nephrol. Basel, Karger, 2007, vol 156, pp 371-386. 